\title{
POLÍTICA DE COTAS RACIAIS NA UNB: UM ESTUDO SOBRE O ACESSO DE NEGROS NA UNIVERSIDADE DURANTE O PERÍODO 2004 A 2012
}

\author{
Amanda Vanessa Pereira de Assunção ${ }^{1}$ \\ Catarina de Almeida Santos ${ }^{2}$ \\ Danielle Xabregas Pamplona Nogueira ${ }^{3}$
}

\section{Resumo}

Em 2003, a Universidade de Brasília (UnB) lançou o Plano de Metas de Integração Social, Étnica e Racial da UnB. Como desdobramento desse Plano, em 2004, foi implementada a política de cotas raciais na Universidade, com o objetivo de proporcionar acesso mais igualitário para alunos negros em todos os cursos ofertados. Após de 10 anos do sistema, a pesquisa foi norteada pela questão: as cotas raciais cumpriram com seu papel de ingresso e redistribuição de alunos negros na UnB? Nesse sentido, o presente artigo tem como objetivo analisar como o programa de cotas raciais contribuiu para o acesso de estudantes negros ao ensino superior na UnB, no período 2004-2012. A pesquisa realizada classifica-se como descritiva. Foram analisados documentos que continham dados a respeito do acesso de negros na UnB e da demanda de candidatos ao sistema de cotas raciais. Conclui-se que o programa de cotas raciais na universidade contribuiu para aumentar o acesso de alunos negros à universidade e redistribuí-los entre os cursos, além de mostrar que os candidatos negros buscam cursos de menor prestígio social e, de forma crescente, cursos da área de saúde.

Palavras-Chave: Negro. Cotas raciais. Acesso. UnB.

\section{RACIAL QUOTAS POLICY AT UNB: A STUDY ON BLACK ACCESS IN THE UNIVERSITY DURING THE PERIOD OF 2004 TO 2012}

\begin{abstract}
In 2003, the University of Brasilia (UnB) launched the Social, Ethnic and Racial Integration Goals Plan of UnB. As an extension of this Plan, in 2004, it was implemented the racial quotas policy at the University, in order to provide more equitable access for black students in all offered courses. After 10 years of the system, the survey was guided by the question: do racial quotas fulfilled their role of entry and redistribution of black students at UnB? In this sense, this article aims to analyze how the racial quota program contributed to the access of black students to higher education at UnB in the period of 2004-2012. This research is classified as descriptive. Documents were analyzed and it contained data about the black access at UnB and the demand of candidates for the racial quota system. We can conclude that the racial quota program at the university helped to increase the access of black students
\end{abstract}


to the university and to redistribute them among the courses, in addition to show that black candidates seek less social prestige courses and, increasingly, healthcare courses.

Keywords: Black. Racial quotas. Access. UnB.

\section{POLÍTICA DE COTAS RACIALES EN LA UNB: UN ESTUDIO SOBRE EL ACCESO DE NEGROS EN LA UNIVERSIDAD DURANTE EL PERÍODO 2004 A 2012}

\section{Resumen:}

En 2003, la Universidad de Brasilia (UnB) lanzó el Plano de Metas de Integración Social, ética y Racial de la UnB. Como despliegue de este Plano, en 2004, fue implantada la política de cuotas raciales en la Universidad, con el objetivo de proporcionar acceso más igualitário a los alumnos negros en todos los cursos ofertados. Despues de 10 años de este sistema, la investigación fue norteada por la pregunta: ¿las cuotas raciales cumplieron su papel de ingresso y redistribución de los alumnos negros en la UnB? En este sentido, el presente artículo tiene como objetivo analizar como el programa de cuotas raciales contribuyó para el acceso de estudiantes negros a la enseñanza superior en la UnB, en el período de 20042012. La investigación realizada se clasifica como descriptiva. Fueron analizados documentos que contenian datos a respecto del acceso de negros a la UnB y de la procura de candidatos al sistema de cuotas raciales. Se concluye que el programa de cuotas raciales en la unversidad contribuyó para aumentar el acceso de alumnos negros a la universidad y redistribuirlos entre los cursos, además de mostrar que los candidatos negros buscan cursos de menor prrestígio social y, de forma cresciente, cursos del área de la salud.

Palabras Clave: Negro. Cuotas raciales. Acceso. UnB.

\section{INTRODUÇÃO}

Segundo Bobbio (1992) a garantia dos direitos do homem não é um problema filosófico e sim político. Ou seja, no geral não temos tantos problemas para justifica-los, mas sim para protegê-lo, tendo em vista que, para ele, quando se trata de "[...] enunciá-los, o acordo é obtido com relativa facilidade, independentemente do maior ou menor poder de convicção de seu fundamento absoluto; quando se trata de passar à ação, ainda que o fundamento seja inquestionável, começam as reservas e as oposições." (BOBBIO, 1992, p. 24).

Em se tratando dos Direitos Humanos, há consenso que a educação é um dos direitos mais fundamentais, tendo em vista ser a base para garantia dos demais direitos. Pode-se observar que a Declaração dos Direitos Humanos, de 1948, declarou que todo cidadão tem 
direito à educação e que esta, por sua vez, tem como objetivo primordial o pleno desenvolvimento do ser humano.

No Caso brasileiro, a educação enquanto direito de todos os indivíduos, declarado em lei, é muito recente e sofreu, no decorrer da história, muitos pequenos avanços e muitos retrocessos. Estudos de autores, como Cury (2002), Oliveira (2007), demonstram que no Brasil, o ensino primário é reconhecido como direito somente a partir de 1934 e que o direito a educação só aparece de forma mais ampla na Constituição de 1988.

A concretização desse direito, no entanto, não tem sido fácil, em que pese as lutas constantes dos movimentos sociais e demais atores envolvidos na busca pela garantia da educação. Em um país de profundas desigualdades sociais e econômicas, lutar por direitos para a maioria não tem sido tarefa fácil. As disparidades de acesso aos bens culturais e a negação dos direitos, se concretizam na exclusão social e racial que tem se perpetuado na sociedade em que vivemos.

Os movimentos sociais, especialmente o movimento negro, são marcados por uma trajetória de luta pelo direito da pulação negra ter acesso à educação. A partir da década de 1990, essas lutas se intensificam e desencadeiam em políticas de ações afirmativas e na elaboração e implementação de políticas específicas em benefício da população negra, sobretudo as políticas de cotas raciais.

Essa luta se justifica, tendo em vista que, apesar dos avanços da última década muito ainda há que ser feito pela inclusão dos negros na educação. Dados do PNAD de 2012 mostram que houve avanço nos últimos anos, mas ainda permanece grande desigualdade entre os anos de estudos de negros e brancos. O gráfico 1 indica que 58,8\% da população negra com 15 anos ou mais de idade no Brasil, tinham até 8 anos de estudos e que apenas $9,4 \%$ possuíam mais de 12 anos de escolaridade, enquanto na população branca esse percentual era de $22,2 \%$.

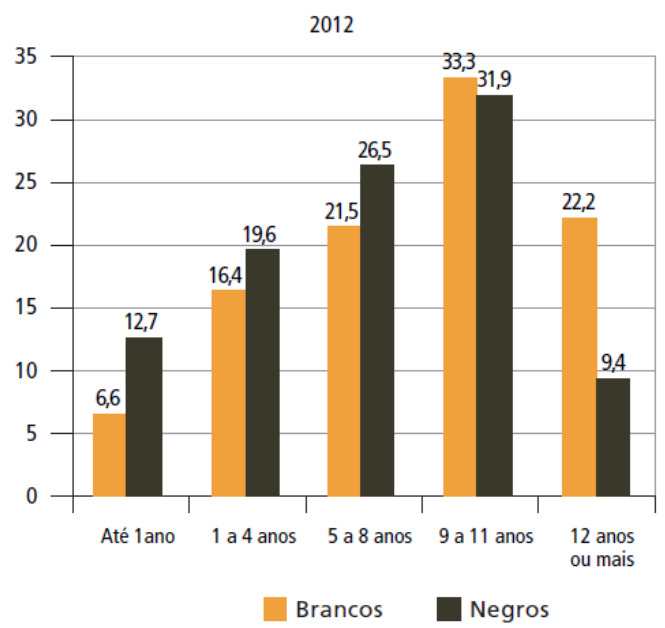




\section{Revista HIISTEYIDIR On-line}

Artigo

doi: $10.20396 /$ rho.v18i1.8645867

Gráfico 1- População com 15 anos de idade ou mais, segundo cor ou raça e faixa de anos de estudo concluídos Brasil, $2012(\%)$.

Fonte: IPEA - Situação social da população negra por estado. Adaptação das autoras.

Nessa perspectiva foi criado o Programa Diversidade na Universidade, no âmbito do Ministério da Educação, por meio da lei 10.558/2002, com a finalidade de implementar e avaliar estratégias para a promoção do acesso ao ensino superior de pessoas pertencentes a grupos socialmente desfavorecidos, especialmente dos afrodescendentes e dos indígenas brasileiros.

No contexto desse Programa, a lei 12.711/2012 estabelece a reserva de vagas, em universidades federais e nas instituições federais de ensino técnico de nível médio, às cotas ( $50 \%$ do total de vagas da instituição) para estudantes que tenham cursado integralmente o ensino médio em escolas públicas.

A aplicação da lei foi feita de forma gradual. Em 2013, a reserva seria de, pelo menos, $12,5 \%$ do número anteriormente ofertada. A implantação das cotas ocorrerá de forma progressiva ao longo de quatro anos, até chegar à metade da oferta total do ensino público superior federal.

Dados da Secretaria de Políticas Públicas de Promoção da Igualdade Racial (SEPPIR) mostraram que, com a adoção da lei 12.711/2012, em 2014, 20\% do total de vagas ofertadas pelas Universidades Federais (48.676) foram ocupadas por estudantes declarados pretos, pardos e indígenas, já $23 \%$ do total de vagas ofertadas pelos Institutos Federais (12.055) foram ocupadas por estudantes da mesma raça e etnia.

$\mathrm{Na}$ Universidade de Brasília (UnB), a política de cotas raciais foi iniciada em 2004, na qual $20 \%$ das vagas dos cursos eram reservadas para o sistema de cotas raciais, aos alunos que se declarassem negros ou pardos.

Nesse sentido, o presente artigo trata da política de cotas raciais em universidades federais, tendo como foco a Universidade de Brasília (UnB), e busca analisar como essa política tem cumprido o seu papel de proporcionar mais acesso de alunos negros na universidade. Trata, especialmente, da análise de como o programa de cotas raciais contribuiu para o acesso de estudantes negros na Universidade de Brasília (UnB), no período 2004-2012.

A pesquisa realizada classifica-se como descritiva. Para Gil (2002), as pesquisas descritivas têm como objetivo primordial a descrição das características de determinada população ou fenômeno ou, então, o estabelecimento de relações entre variáveis podendo salientam as pesquisas que têm por objetivo estudar as características de um grupo: sua distribuição por idade, sexo, procedência, nível de escolaridade, estado de saúde física e mental e etc. 
A pesquisa analisou documentos a respeito do acesso de negros na UnB por meio do sistema de cotas. Após a pesquisa documental, os dados foram analisados buscando-se identificar qual a efetividade do sistema de cotas na UnB, com destaque aos cenários dos cursos que garantiram esse acesso.

\section{POLÍTICAS SOCIAIS E O NEGRO NA UNIVERSIDADE}

O conceito de política social engloba a busca de melhoria na qualidade de vida da população, partindo da garantia de direitos sociais, dentre eles, a educação. Para assegurar que todos os membros do Estado tenham acesso a esses direitos, as políticas públicas sociais podem ser universais ou focalizadas.

Em relação às políticas universais, Kerstenetzky (2006) frisa que estas economizam vários recursos na alocação do gasto social, em particular, os custos associados ao desenho minucioso, à implementação e ao monitoramento de políticas focalizadas, e posterior avaliação dos impactos, necessária para a correção incremental dos "vazamentos" ou "exclusões" indevidos.

Para Barco (2010), as políticas focalizadas são parte da relação entre Estado, Família e Mercado para atingir o bem-estar, definida por embasamentos técnicos que orientam a construção de um mix público/privado nas áreas dos serviços sociais, reestruturando a matriz básica do público, além de terem a descentralização como uma estratégia para alcançar seus objetivos, que são: reduzir o gasto social, gerir eficientemente os recursos do Estado e criar uma rede de segurança social mínima.

As políticas consideradas focalizadas podem se subdividir em três categorias: residual, condicional e reparatória. Segundo Kerstenetzky (2006), a residual está intimamente ligada ao modelo neoliberal; a condicional está voltada para a boa utilização dos recursos públicos a fim de garantir as áreas carentes, e a reparatória ou redistributiva, que visaria alguns grupos a fim de se garantir a igualdade aos direitos sociais.

A partir do entendimento de política reparatória, dois conceitos merecem ser tratados: compensação e emancipação. De acordo com Feliciano e David (2014), a compensação se define como uma forma de se extinguir uma obrigação entre os sujeitos da relação obrigacional (este termo é usado no sentido de equilibrar); e a emancipação, como o ato de equiparar o padrão legal de cidadãos, oportunizando a igualdade de status de cidadãos em relação ao Estado.

Moraes (2009) afirma que as ações afirmativas são exemplos de medidas compensatórias, pois visam a garantir e a promover os direitos da igualdade de oportunidades combinados ao reconhecimento de um tratamento desigual para os desiguais sendo assim são destinadas a grupos com pertencimento étnico-racial que se encontram sub- 


\section{Revista HIISTEYIDIR On-line}

representados em virtude de discriminação sofrida no passado ainda fortemente presente na sociedade.

Com base nos conceitos apresentados, o sistema de cotas raciais se apresenta como uma política compensatória, tendo em vista que essa política busca a equiparação de direitos entre negros e brancos, além da quebra de culturas e crenças que colocam o negro como inferior ao branco. Assim, a política de cotas raciais visa reparar danos de geração passadas, voltada a negros. É, também, política reparatória, relacionada a políticas universais devido a atenção a direitos sociais, buscando a diminuição dos impactos causados pela criação de uma cultura injusta, como se observa no caso racial, sobretudo no contexto educacional.

O Relatório Anual das Desigualdades Raciais no Brasil (2009-2010) mostra que houve aumento de alunos que frequentam o ensino superior, mas ainda há de se notar uma disparidade de frequência entre negros e brancos, conforme tabela 1.

Tabela 1 - Taxa líquida de escolaridade no ensino superior entre brancos, pretos e pardos (18 a 24 anos)

\begin{tabular}{l|l|l|l|l}
\hline \multicolumn{2}{c|}{} & $\mathbf{1 9 8 8}$ & $\mathbf{1 9 9 8}$ & $\mathbf{2 0 0 8}$ \\
\hline \multirow{3}{*}{ Homens } & Brancos & 12,3 & 15,0 & 31,7 \\
\cline { 2 - 5 } & Pretos e Pardos & 3,1 & 3,2 & 13,0 \\
\cline { 2 - 5 } & Total & 8,2 & 9,4 & 21,6 \\
\hline \multirow{4}{*}{ Mulheres } & Brancas & 12,4 & 18,4 & 39,9 \\
\cline { 2 - 5 } & Pretas e Pardas & 4,1 & 5,0 & 20,0 \\
\cline { 2 - 5 } & Total & 8,9 & 12,3 & 29,6 \\
\hline \multirow{3}{*}{ Total } & Brancos & 12,4 & 16,8 & 35,8 \\
\cline { 2 - 5 } & Pretos e Pardos & 3,6 & 4,0 & 16,4 \\
\cline { 2 - 5 } & Total & 8,6 & 10,9 & 25,5 \\
\hline
\end{tabular}

Fonte: Tabela elaborada pelas autoras com base nos dados de Paixão, 2010.

Ao observar a tabela, observa-se, ainda, que, apesar dos negros ainda serem minoria no acesso ao ensino superior, o acesso destes tem aumentado. Deve-se levar em conta neste aumento, o acesso não somente a universidades públicas, mas, também, o acesso a universidades particulares, levando-se em conta que há uma maior oferta de vagas nessa rede de ensino, além de programas do governo que financiam alunos nas IES,s particulares. São exemplos os Programas como o Fundo de Financiamento ao Estudante do Ensino Superior (Fies) e o Programa Universidade para Todos (ProUni), que tem como finalidade a concessão de bolsas de estudos integrais e parciais a estudantes de cursos de graduação e de cursos sequenciais de formação específica, em instituições privadas de educação superior que aderem ao programa por isenção de tributos.

No entanto, o acesso de negros à educação superior por meio do sistema de cotas não apresenta consenso entre os autores. Cardoso (2008) mostra que no Brasil existem três grandes argumentos que cercam a polemica acerca das cotas raciais, que são: 1. Noções de meritocracia que alegam que as vagas da universidade devem ser destinadas somente aos 
mais aptos; 2. Disputa racial, o sistema cria uma espécie de ódio entre dois grupos - os que tem direito ao privilégio e os que não têm; 3 . O método de aprovação no sistema é alvo de discussões.

Uma das críticas à reserva de vagas baseia-se no argumento de que deficiências na formação escolar anterior dos cotistas consistiriam em ameaça à qualidade do ensino universitário, mas o argumento não tem encontrado apoio em dados empíricos sobre o rendimento no curso de cotistas em várias universidades. (VELLOSO, 2009). Os resultados do primeiro semestre de estudos dos aprovados na UnB em 2004 revelaram que, no conjunto de todos os alunos, mais de $1 / 3$ dos cotistas se situavam na metade superior da distribuição do índice de rendimento acadêmico em seus respectivos cursos, ao lado dos melhores estudantes aprovados pelo sistema universal. (VELLOSO, 2006 apud VELLOSO, 2009).

A política de cotas raciais, então, se efetiva com o ideal de incentivar alunos negros a buscar o ingresso na universidade pública, visando reverter uma das formas de racismo encontradas na sociedade moderna. Apesar de ser um sistema que com o passar dos anos passou por modificações em busca da redução de falhas na aceitação de candidatos ao sistema, os critérios de seleção ainda levam a contradições acerca da chamada institucionalização do racismo.

Mesmo com as discussões antagônicas que cercam esse tema, a política de cotas raciais em universidades públicas e tem se apresentado como uma tentativa do Estado de democratizar o acesso de todos a esses ambientes que são competitivos para entrar, buscando a garantia do direito à educação e a diminuição da desigualdade social.

\section{AS COTAS RACIAIS NA UNIVERSIDADE DE BRASÍLIA}

A Universidade de Brasília foi fundada em 21 de abril de 1962. Oferece, atualmente, 109 cursos de graduação, sendo 31 noturnos e 10 a distância. Há, ainda, 147 cursos de pósgraduação stricto sensu e 22 especializações lato sensu. Os cursos estão divididos em quatro campi espalhados pelo Distrito Federal: Darcy Ribeiro (Plano Piloto), Planaltina, Ceilândia e Gama. Os órgãos de apoio incluem o Hospital Universitário, a Biblioteca Central, o Hospital Veterinário e a Fazenda Água Limpa.

A Universidade foi idealizada por dois grandes nomes da educação brasileira: Darcy Ribeiro e Anísio Teixeira. Em 1964, com o Golpe Militar, o campus foi cenário de invasões das tropas militares que buscavam estudantes e professores, tendo a invasão mais violenta em 1968. Na ocasião, agentes das polícias Militar, Civil, Política (Dops) e do Exército invadiram a UnB e detiveram mais de 500 pessoas na quadra de basquete. Um estudante foi baleado. As invasões só acabaram quando iniciou a abertura política no Brasil, em 1979. A democracia só retornou à Universidade em 1984, com a eleição o primeiro reitor eleito pela 
comunidade universitária, como desafio de reerguer a instituição de vanguarda idealizada por seus fundadores. (UNIVERSIDADE DE BRASÍLIA, 2013).

Nas últimas décadas, a Universidade tem cumprido a função de levantar o debate sobre temas polêmicos na sociedade. Em 1996, a UnB implementou o Programa de Avaliação Seriada (PAS), uma alternativa ao vestibular, tradicional forma de ingresso no ensino superior. A instituição também foi a primeira a adotar o sistema de cotas no vestibular, de maneira a promover a inclusão de negros e indígenas, em 2003.

A principal forma de ingresso à Universidade ao longo dos anos se consolidou por meio de Vestibular tradicional - aplicado desde sua fundação, em 1962, e cuja prova é elaborada pela própria Universidade de Brasília. Desde 2014, deixou de ser aplicada duas vezes ao ano, passando a se realizar apenas para ingresso de estudantes no segundo semestre. Esse se subdivide em dois sistemas concorrência (Sistema Universal), Sistema de Cotas para Escolas Públicas e o Sistema de Cotas para Negros da UnB.

No Sistema de Cotas para Escolas Públicas se subdivide, ainda, em outros dois grupos, sendo metade das vagas para candidatos que estudaram integralmente o ensino médio em escola pública e possuem renda familiar igual ou inferior a um salário mínimo e meio per capita, e a outra parte destinada aos que também estudaram integralmente o ensino médio em escola pública e possuem renda familiar superior a um salário mínimo e meio per capita. Em ambas as situações, no processo de classificação, os casos de candidatos que se declararem pretos, pardos ou indígenas (PPI).

Outro sistema de ingresso é o Programa de Avaliação Seriada (PAS), que foi criado pela UnB em 1996, como uma alternativa ao ingresso na universidade. Objetiva integrar a educação básica e superior para promover melhorias na qualidade do ensino, realizado no $1^{\circ}$ semestre do ano, ocorrendo ao final de cada série do ensino médio. $\mathrm{O}$ ingresso também pode ser por meio do Processo de seleção destinado a candidatos interessados em cursos oferecidos pela UnB na modalidade de Educação a Distância $(\mathrm{EaD})$ por meio do Sistema Universidade Aberta do Brasil (UAB), ocorrendo no $2^{\circ}$ semestre de cada ano.

Também como forma de ingresso, o Sistema de Seleção Unificada (Sisu) é realizado no primeiro semestre de cada ano. É um sistema informatizado, implantado pelo Ministério da Educação (MEC) em 2010, que utiliza a nota do último Exame Nacional do Ensino Médio (Enem) para classificar os candidatos à vaga no ensino superior público.

Há, ainda: o sistema de Vagas remanescentes - Seleção específica para preenchimento de vagas que não foram ocupadas nos processos de seleção aplicados anteriormente, como PAS e Sisu, ocorrendo no $1^{\circ}$ semestre do ano; Vestibular para licenciatura em educação no campo - processo de seleção destinado a ampliar a oferta de vagas no ensino superior público com o objetivo de formar professores para atuar na educação básica em escolas do campo na região do Distrito Federal (DF) e Goiás (GO), ocorrendo no $2^{\circ}$ semestre de cada ano e o chamado vestibular indígena - processo de seleção 
destinado à inclusão de estudantes indígenas que vivem em comunidades espalhadas pelo interior do país, ocorrendo no $1^{\circ}$ e $2^{\circ}$ semestre de cada ano.

O sistema de cotas na UnB tem um marco inicial, a III Conferência Mundial contra o Racismo, em 2001. Segundo Barros (2002), a conferência visava mapear as distintas formas de racismo, identificar os grupos étnicos e raciais mais sujeitos aos efeitos de sua manifestação, como também propor ações aos Estados-membros e aos órgãos das Nações Unidas, buscando-se evidenciar as lutas contra a opressão e do combate ao racismo no plano global tratando também sobre as 'intolerâncias correlatas', como um oportuno ponto de entrada para a ampliação da discussão sobre a multiplicidade de opressões relativas à orientação sexual e aos direitos sexuais, estando entre as propostas a adoção de cotas ou outras medidas afirmativas que promovessem o acesso de negros às universidades públicas.

No contexto dessa Conferência, o "Caso Ari" se apresentou como elemento motivador para a discussão de cotas na UnB.

Em 1998, o aluno Arivaldo Lima Alves, estudante do curso de doutorado do Departamento de Antropologia da Universidade de Brasília (UnB), foi reprovado em uma disciplina obrigatória. Em 20 anos daquele programa de pós-graduação foi o primeiro aluno a ser reprovado. Dois anos após a reprovação, o Conselho de Ensino, Pesquisa e Extensão forçou o departamento a rever a menção e Arivaldo foi aprovado. O episódio, conhecido como "Caso Ari", estimulou o orientador de Arivaldo, o professor José Jorge de Carvalho, a elaborar no ano seguinte a primeira proposta de cotas. (UNIVERSIDADE DE BRASÍLIA, 2009).

Os fatos mencionados impactaram a criação do edital de cotas para negros em universidades federais. No dia 8 de março de 2002, os professores do Departamento de Antropologia da UnB José Jorge de Carvalho e Rita Laura Segato apresentam ao Conselho de Ensino, Pesquisa e Extensão da UnB um documento de 70 páginas provando a discriminação racial e defendendo as cotas.

Carvalho e Segato (2002, p. 40) apresentaram o documento que concluía que as cotas raciais se mostram importantes, de maneira que:

1. Os negros, que representam $45 \%$ da população do país, somam apenas $2 \%$ da população universitária brasileira; os brancos e amarelos, que representam $54 \%$ da população, detêm $98 \%$ das vagas atuais do ensino superior; 2 . Na UnB, $99 \%$ dos professores são brancos e em torno de $90 \%$ dos alunos são brancos; 3. Já contamos com um contingente suficiente de negros preparados para cursar nossas universidades, porém que não conseguem vencer a competição desleal com os brancos de melhor renda que pagam cursinhos mais poderosos; 4 . Temos que construir uma academia que reflita a diversidade racial e étnica da nossa nação, para que possa pensar melhor as soluções urgentes de que precisamos para resolver os graves problemas da nossa sociedade.

Como resultado dessas ações, em 6 de junho de 2003, foi lançado o Plano de Metas de Integração Social, Étnica e Racial da UnB, que inclui o acesso e a permanência de negros e indígenas, via política de ação afirmativa e programa de apoio ao ensino público do Distrito 
Federal, é aprovado pelo Conselho de Ensino, Pesquisa e Extensão (CEPE) da UnB. Tem como objetivos: "[...] atender à necessidade de gerar, na Universidade de Brasília, uma composição social, étnica e racial capaz de refletir minimamente a situação do Distrito Federal e a diversidade da sociedade brasileira como um todo." (CARVALHO; SEGATO, 2002, p. 1).

O Plano de Metas possui três pontos básicos: 1 . O acesso de negros e indígenas, via política de ação afirmativa; 2. A permanência do estudante que ingressa, via política de ação afirmativa; 3. Programa de apoio ao ensino público do Distrito Federal.

De acordo com o Plano, a partir do segundo vestibular de 2004, os candidatos poderiam concorrer pelo sistema universal ou pelo sistema de cotas, que oferecem, respectivamente, $80 \%$ e 20\% das vagas de cada curso. Além disso, o Plano de Metas prevê acompanhamento acadêmico e psicossocial para os alunos cotistas e para os índios.

Garcia (2013) afirma que, com relação ao acesso à UnB, o Plano de Metas também estabeleceu um caráter social para as escolas públicas de ensino médio do Distrito Federal. Trata-se de um programa de acompanhamento permanente, implementado para os alunos interessados em se inscrever no vestibular da UnB, com apoio específico para aqueles que pretendiam ingressar em cursos de alta competitividade, como Medicina e Direito. Objetivou-se, assim, promover uma maior igualdade de oportunidades para os estudantes da escola pública comparativamente aos estudantes oriundos das escolas particulares, em geral melhor preparados para a competição do vestibular.

O sistema de cotas raciais na Universidade de Brasília (UnB) começou a vigorar no segundo semestre de 2004, tendo como limite de existência o primeiro semestre de 2014, ao completar dez anos de existência.

Durante esses dez anos, o sistema de cotas raciais sofreu algumas modificações com relação a maneira de identificação de alunos que fossem considerados ou não negros para assim se enquadrarem no sistema. De acordo com o relatório de própria universidade, assim que o programa foi implementado, o candidato que quisesse concorrer às vagas reservadas para o sistema de cotas deveria se apresentar nos postos de inscrição situados na UnB, com uma ficha de inscrição preenchida. No posto de atendimento da universidade, o candidato seria fotografado e teria a sua foto anexada a ficha de inscrição que passaria por uma banca examinadora, cabendo ressaltar que esse tramite acontecia antes da realização do vestibular. (UNIVERSIDADE DE BRASÍLIA, 2013).

A partir do primeiro semestre de 2008, o candidato que desejasse concorrer às vagas reservadas para o sistema de cotas raciais deveria se submeter a uma entrevista com uma banca avaliadora. Essa entrevista ocorreria após a realização do vestibular e o candidato se submeteria a responder algumas perguntas, tais como “[...] você se considera negro?", além de ter a ciência de que a entrevista seria gravada. (UNIVERSIDADE DE BRASÍLIA, 2013, 
p. 4). A mudança no modo de avaliação ocorreu devido ao caso dos gêmeos univitelinos Alan e Alex, no qual Alan foi aceito pelos critérios da universidade e Alex não.

Cabe ressaltar que o edital para cotas raciais havia definido que o aluno que não tivesse sua inscrição homologada para o sistema de cotas raciais passaria a concorrer no sistema de vagas universal, não havendo a necessidade do candidato se submeter a outra entrevista após a homologação de sua inscrição para o sistema de cotas raciais. (UNIVERSIDADE DE BRASÍLIA, 2013).

Dados do mesmo relatório disponibilizado pela UnB mostram que do segundo semestre de 2004 ao primeiro semestre de 2013, 64.683 candidatos se inscreveram para as vagas de cotas para negros, conforme tabela 02 .

Tabela 02 - Candidatos inscritos pelo sistema de cotas para negros e homologados, no período de 2004 a 2013

\begin{tabular}{c|c|c|c}
\hline Número de & $\begin{array}{c}\text { Número de } \\
\text { Hnscritos }\end{array}$ & $\begin{array}{c}\% \text { aproximada de } \\
\text { Homologados }\end{array}$ \\
\hline $2^{\mathbf{o}}$ vestibular de 2004 & 4385 & 4194 & $96 \%$ \\
\hline $1^{\mathbf{o}}$ vestibular de 2005 & 4913 & 4300 & $88 \%$ \\
\hline $2^{\mathbf{o}}$ vestibular de 2005 & 3816 & 2241 & $59 \%$ \\
\hline $1^{\mathbf{o}}$ vestibular de 2006* & 2454 & 2473 & $101 \%$ \\
\hline $2^{\mathbf{o}}$ vestibular de 2006 & 3901 & 2006 & $51 \%$ \\
\hline $1^{\mathbf{o}}$ vestibular de 2007 & 3660 & 1831 & $50 \%$ \\
\hline $2^{\mathbf{o}}$ vestibular de 2007 & 3673 & 2228 & $61 \%$ \\
\hline $1^{\mathbf{o}}$ vestibular de 2008 & 4083 & 1136 & $28 \%$ \\
\hline $2^{\mathbf{o}}$ vestibular de 2008 & 2713 & 1259 & $46 \%$ \\
\hline $1^{\mathbf{o}}$ vestibular de 2009 & 3262 & 901 & $28 \%$ \\
\hline $2^{\mathbf{o}}$ vestibular de 2009 & 3416 & 1291 & $38 \%$ \\
\hline $1^{\mathbf{o}}$ vestibular de 2010 & 3577 & 1117 & $46 \%$ \\
\hline $2^{\mathbf{o}}$ vestibular de 2010 & 3339 & 1522 & $42 \%$ \\
\hline $1^{\mathbf{o}}$ vestibular de 2011 & 3815 & 1590 & $55 \%$ \\
\hline $2^{\mathbf{o}}$ vestibular de 2011 & 3702 & 2045 & $43 \%$ \\
\hline $1^{\mathbf{o}}$ vestibular de 2012 & 3933 & 1693 & $53 \%$ \\
\hline $2^{\mathbf{o}}$ vestibular de 2012 & 3032 & 1617 & $41 \%$ \\
\hline $1^{\mathbf{o}}$ vestibular de 2013 & 3009 & 1235 & \\
\hline
\end{tabular}

Fonte: Tabela elaborada pelas autoras com base nos dados UnB, 2013.

*No primeiro semestre de 2006 não foi possível saber o quantitativo correto de inscritos e os 19 candidatos homologados a mais se referem aos candidatos de presídios, onde o processo de inscrição foi separado (dados da Coordenadoria de Tecnologia do CESPE/UnB).

\section{O ACESSO DE NEGROS NA UNIVERSIDADE DE BRASÍLIA NO PERÍODO DE 2/2004 A 2/2006}


A pesquisa foi desenvolvida com base na dissertação de Cardoso (2008), na qual são exploradas informações acerca da demanda, desempenho, rendimento acadêmico e no vestibular e o índice de evasão acerca dos vestibulares de 2004, 2005 e 2006 da UnB. Para a pesquisa, considerou-se somente o segundo semestre de cada ano. São observadas também algumas variáveis, tais como o sistema de inscrição (universal e cotas), idade, sexo, opção por língua estrangeira no vestibular.

A partir da pesquisa de Cardoso (2008), foi possível definir quatro categorias de análise para a pesquisa proposta, a saber: procura pela UnB; demanda das cotas; cursos para os quais os cotistas se candidatam; e, cotas nos cursos de alto prestígio.

\section{a) PROCURA PELA UNIVERSIDADE DE BRASÍLIA E DEMANDA DAS COTAS}

A tabela 3 mostra que nos primeiros anos da política racial na universidade, a quantidade de inscritos no primeiro ano foi expressiva, o que demonstra que a política conseguiu alcançar o público esperado.

Tabela 03 - Total de Inscritos no vestibular no período de 2/2004 a 2/2006

\begin{tabular}{c|c|c|c}
\hline & \multicolumn{2}{|c|}{ Inscritos } & Total \\
\hline Período & Universal & Cotas & \\
\hline $2^{\mathbf{o}} 2004$ & 23.196 & 4.194 & 27.390 \\
\hline $2^{\mathbf{o}} 2005$ & 20.452 & 4.042 & 24.494 \\
\hline $2^{\mathbf{o}} 2006$ & 19.694 & 2.006 & 21.700 \\
\hline
\end{tabular}

Fonte: Tabela elaborada pelas autoras com base nos dados de UnB, 2013.

Na tabela acima é possível observar que houve uma queda na quantidade de inscritos pelo sistema universal e as cotas acompanharam esse movimento. Essa observação também pode ser analisada pelos dados da tabela 04 , a qual demonstra o decréscimo nas inscrições no sistema de cotas.

Tabela 04 - Cotistas Inscritos e Homologados no período de 2/2004 a 2/2002

\begin{tabular}{l|c|c}
\hline Período & Inscritos & Homologados \\
\hline $\mathbf{2 / 2 0 0 4}$ & 4.385 & 4.194 \\
\hline $\mathbf{2 / 2 0 0 5}$ & 3.816 & 2.241 \\
\hline $\mathbf{2 / 2 0 0 6}$ & 3.901 & 2.006 \\
\hline
\end{tabular}

Fonte: Tabela elaborada pelas autoras com base nos dados de UnB,2013.

Sobre esse movimento, Cardoso (2008) conclui que, no primeiro triênio da política, a diminuição da demanda de alunos para o sistema de cotas raciais remete à ideia de que a demanda de alunos às instituições particulares de ensino aumentou em razão de políticas 
como Fies e Prouni, que passaram a absorver alunos de baixa renda, grande parte do público sistema de cotas.

\section{b) CURSOS OS QUAIS OS COTISTAS SE CANDIDATAM}

Para um maior entendimento, Cardoso (2008), explica que a divisão acerca do grau de prestigio dos cursos ocorre de maneira que a UnB adota três categorias em seu vestibular: Humanidades, Ciências e Saúde. Para fins de pesquisa, esses grupos foram agrupados por prestigio social das carreiras que segue o agrupamento adotado por Velloso (2005). Essa forma de agregação é construída com base na média de desempenho dos aprovados em cada curso. Foram construídas três categorias de grupo: Alto prestígio, sendo os cursos que possuem argumento final superiores a meio desvio padrão acima da média; Médio prestígio, sendo os que possuem meio desvio padrão acima e meio desvio padrão abaixo da média e Baixo prestígio, os que possuem argumento final inferior a meio desvio padrão abaixo da média.

O Quadro 1 traz exemplos dos cursos e de sua classificação segundo o modelo apresentado por Velloso (2005).

Quadro 01 - Exemplo de cursos no agrupamento por prestígio social

\begin{tabular}{|c|c|c|}
\hline Área & Grupo & Exemplo de Cursos \\
\hline \multirow{4}{*}{ Humanidades } & Alto Prestígio & Comunicação, Direito, Economia \\
\cline { 2 - 3 } & Médio Prestígio & Administração, Filosofia, Desenho Industrial \\
\cline { 2 - 3 } Ciências & Baixo Prestígio & Pedagogia, Serviço Social, Biblioteconomia \\
\hline \multirow{4}{*}{ Saúde } & Alto Prestígio & Engenharia Elétrica, Mecânica, Mecatrônica \\
\cline { 2 - 3 } & Médio Prestígio & Agronomia, Engenharia Civil, Física \\
\cline { 2 - 3 } & Baixo Prestígio & Engenharia Florestal, Geologia, Matemática \\
\hline & Alto Prestígio & Medicina \\
\cline { 2 - 3 } & Médio Prestígio & Nutrição, odontologia, Psicologia \\
\cline { 2 - 3 } & Baixo Prestígio & Enfermagem, Educação Física \\
\hline
\end{tabular}

Fonte: Quadro elaborado pelas autoras com base nos dados de Velloso, 2005.

De acordo com os dados da tabela 05, Cardoso (2008) observou que a proporção de cotistas nos cursos de baixo prestígio é basicamente o dobro da verificada nos cursos de alto prestigio, sendo $14 \%$ e $7 \%$, respectivamente. Esse fato pode estar ocorrendo devido a um possível desfavorecimento socioeconômico para com os candidatos do sistema universal, fazendo com que os cotistas ${ }^{5}$ optem por cursos com nota de corte mais baixa no vestibular, devido a uma baixa expectativa de obtenção de sucesso na prova. 
Tabela 05 - Percentual de cotistas por área de grupo de curso no período de 2/2004 a 2/2006

\begin{tabular}{c|l|r|r|r}
\hline Área & Grupo de curso & $\mathbf{2 / 2 0 0 4}$ & $\mathbf{2 / 2 0 0 5}$ & $\mathbf{2 / 2 0 0 6}$ \\
\hline \multirow{4}{*}{ Humanidades } & Alto Prestígio & 15 & 10 & 5 \\
\cline { 2 - 5 } & Médio Prestígio & 10 & 10 & 4 \\
\cline { 2 - 5 } & Baixo Prestígio & 10 & 9 & 4 \\
\hline \multirow{4}{*}{ Saúncias } & Alto Prestígio & 6 & 7 & 3 \\
\cline { 2 - 5 } & Médio Prestígio & 5 & 8 & 3 \\
\cline { 2 - 5 } & Baixo Prestígio & 7 & 8 & 4 \\
\hline & Alto Prestígio & 32 & 32 & 21 \\
\cline { 2 - 5 } & Médio Prestígio & 9 & 13 & 6 \\
\cline { 2 - 5 } & Baixo Prestígio & 25 & 18 & 7 \\
\hline
\end{tabular}

Fonte: Tabela elaborada pelas autoras com base nos dados de Cardoso (2008).

Observa-se que, no primeiro ano de vigência das cotas raciais, havia uma boa distribuição de alunos cotistas nas camadas da área de humanidades e uma ampla concorrência destes na área de saúde. Entretanto, cabe observar que na área de ciências o percentual de cotistas se mostra inferior a das demais áreas.

No ano de 2005, observa-se que a demanda para os cursos de alto prestigio de humanidades sofreu uma ligeira queda. Entretanto, na área de ciências todas as áreas sofrem um ligeiro acréscimo. $\mathrm{Na}$ área de saúde, apesar de o número de cotistas cair nos cursos de baixo prestígio, os cursos de médio prestígio sofreram um ligeiro acréscimo, podendo-se concluir que na área de saúde a demanda foi constante

No ano de 2006, a demanda de todas as áreas caiu, e o total de alunos que buscaram a universidade também, mostrando que a queda na procura pela universidade ocorreu como um todo. A partir deste fato, Cardoso (2008), conclui que esta queda na procura pode ter decorrido da expansão do ensino privado no Distrito Federal que em 2005 teve o ProUni foi institucionalizado pela Lei $\mathrm{n}^{\circ} 11.096$, ganhando força em 2006, o que explicaria a queda na procura pela UnB

Ressalta-se que apesar de um baixo percentual de aumento de vagas no último ano do primeiro triênio, as cotas raciais ainda sim, representam um estimulo para mais alunos negros tentarem ingressar na universidade.

\section{c) COTAS NOS CURSOS DE ALTO PRESTÍGIO}

A tabela 06 mostra a evolução da demanda de candidatos, nos cursos considerados de alto prestígio, no primeiro triênio de vigência da política. 


\section{Revista HIIS'TNIDBR (Dn-lime}

Tabela 06 - Demanda de cotistas e não cotistas nos cursos de alto prestígio no período de 2/2004 a $2 / 2006$

\begin{tabular}{c|r|r|r|r|r|r}
\hline \multirow{2}{*}{ Área } & \multicolumn{2}{|c|}{$\mathbf{2 / 2 0 0 4}$} & \multicolumn{2}{c|}{$\mathbf{2 / 2 0 0 5}$} & \multicolumn{2}{c}{$\mathbf{2 / 2 0 0 6}$} \\
\cline { 2 - 8 } & Universal & Cotas & Universal & Cotas & Universal & Cotas \\
\hline Humanidades & 23 & 15 & 18 & 10 & 19 & 5 \\
\hline Ciências & 14 & 6 & 13 & 7 & 13 & 3 \\
\hline Saúde & 74 & 32 & 74 & 32 & 77 & 21 \\
\hline
\end{tabular}

Fonte: Tabela elaborada pelas autoras com base nos dados de Cardoso (2008).

Observa-se que nos cursos de saúde houve uma maior demanda de alunos cotistas ao longo dos anos, onde mesmo com a expansão da rede privada, a demanda na área de saúde se manteve mais constante que nas demais áreas. Ressalta-se que em 2006 a quantidade de cotistas caiu juntamente com a quantidade total de inscritos no vestibular, apesar das oscilações para os candidatos não cotistas serem menores.

\section{O ACESSO DE NEGROS NA UNIVERSIDADE DE BRASÍLIA NO PERÍODO DE 2/2007 A 2/2012}

Com base na dissertação de Cardoso (2008), essa pesquisa analisou somente o segundo vestibular de cada ano, tendo em vista que o primeiro vestibular do ano possuiu cinquenta por cento das vagas reservadas para o Programa de Avaliação Seriado - PAS e, atualmente, há vagas que se destinam ao Exame Nacional do Ensino Médio - ENEM.

Para fins de pesquisa, sempre que o termo "cotista" for apresentado, estará se referindo ao "Cotista Negro". Apesar de a universidade possuir uma reserva de vagas para alunos de escola pública e indígenas, estes não são objeto de pesquisa desse trabalho.

Conforme apresentado anteriormente, o ingresso à Universidade é possível de quatro maneiras diferentes, sendo elas: Vestibular tradicional; PAS - Programa de Avaliação Seriada; EaD/UAB; e, ENEM/SISU. Desses, somente através do vestibular é possível ter acesso ao sistema de cotas raciais.

Para fins de análise do período completo em vigoraram as cotas raciais, também foram analisados o relatório, disponibilizado pela própria Universidade de Brasília, e os dados de demanda nos vestibulares, disponibilizados pelo Cespe.

\section{a) PROCURA PELA UNB E DEMANDA DAS COTAS}

A tabela 07 mostra que houve um aumento nos anos de 2007 e 2008, para ambos os sistemas, fazendo com que nos anos seguintes a demanda mantivesse um certo parâmetro mesmo com as oscilações. 


\section{Revista HIIS'TNIDBR (Dn-lime}

Artigo

doi: $10.20396 /$ rho.v18i1.8645867

Tabela 07- Total de Inscritos no vestibular no período de 2/2007 a 2/2012

\begin{tabular}{c|c|c|c}
\hline & \multicolumn{2}{|c|}{ Inscritos } & Total \\
\hline Período & Universal & Cotas & \\
\hline $2^{\mathbf{o}} 2007$ & 22.625 & 3.673 & 24.492 \\
\hline $2^{\mathrm{o}} 2008$ & 21.061 & 2.713 & 23.827 \\
\hline $2^{\mathrm{o}} 2009$ & 20.532 & 3.416 & 24.024 \\
\hline $2^{\mathrm{o}} 2010$ & 18.452 & 3.339 & 21.791 \\
\hline $2^{\mathrm{o}} 2011$ & 21.270 & 3.702 & 24.972 \\
\hline $2^{\mathbf{o}} 2012$ & 18.336 & 3.032 & 21.368 \\
\hline
\end{tabular}

Fonte: Tabela elaborada pelas autoras com base nos dados de UnB, 2013.

Conclui-se que, o aumento da busca pela universidade nos anos de 2007 e 2008, ocorreu graças a implementação do Programa de Apoio a Planos de Reestruturação e Expansão das Universidades Federais - REUNI. O Programa foi instituído pelo Decreto $\mathrm{n}^{\circ}$ 6.096, de 24 de abril de 2007, possuindo como um de seus objetivos, dotar as universidades federais das condições necessárias para ampliação do acesso e permanência na educação superior, apresentando-se como uma das ações do Plano de Desenvolvimento da Educação - PDE.

Com a implementação do programa, a Universidade de Brasília chegou, em 2012, com 8.428 vagas disponíveis para a graduação em cursos presenciais, possuindo uma oferta duas vezes maior que a de 2007 , quando havia 4.188 vagas.

Se por um lado observou-se o aumento de candidatos em 2008, por outro, o número de candidatos cotistas que tiveram suas inscrições homologadas diminuiu. Um fator que pode ajudar a explicar esse movimento se refere à alteração do método de reconhecimento de candidatos.

Tabela 08 - Cotistas Inscritos e Homologados no período de 2/2006 a 2/2012

\begin{tabular}{l|c|c}
\hline Período & Inscritos & Homologados \\
\hline $\mathbf{2 / 2 0 0 7}$ & 3.673 & 2.228 \\
\hline $\mathbf{2 / 2 0 0 8}$ & 2.713 & 1.259 \\
\hline $\mathbf{2 / 2 0 0 9}$ & 3.416 & 1.291 \\
\hline $\mathbf{2 / 2 0 1 0}$ & 3.339 & 1.522 \\
\hline $\mathbf{2 / 2 0 1 1}$ & 3.702 & 2.045 \\
\hline $\mathbf{2 / 2 0 1 2}$ & 3.032 & 1.617 \\
\hline
\end{tabular}

Fonte: Tabela elaborada pelas autoras com base nos dados de UnB, 2013.

Coincidentemente com a implementação do ReUni, ocorreu também a alteração de reconhecimento de candidatos aptos a participarem do sistema de cotas. Apesar da demanda de alunos cotistas se manter com baixas oscilações, a quantidade de inscrições homologadas pelo sistema diminui a cada ano. 
Entretanto há de se observar que, em 2011, não ocorreu nenhuma alteração no sistema de reconhecimento de candidatos e após a implementação do ReUni, foi o ano em que mais candidatos tiveram suas inscrições homologadas. Assim, pode-se concluir que talvez os alunos que estivessem se candidatando não fossem realmente negros.

\section{b) CURSOS OS QUAIS OS COTISTAS SE CANDIDATAM}

A tabela 09 mostra o percentual de alunos cotistas que buscaram a universidade durante os anos que sucederam a implementação do ReUni, buscando observar se apesar da queda de candidatos homologados pelo sistema, ocorreu alguma mudança em relação a demanda de candidatos aos cursos.

Tabela 09 - Percentual de cotistas por área de grupo de curso no período de 2/2007 a 2/2012

\begin{tabular}{c|l|r|r|r|r|r|r}
\hline \multicolumn{1}{c}{ Área } & Grupo de curso & $\mathbf{2 / 2 0 0 7}$ & $\mathbf{2 / 2 0 0 8}$ & $\mathbf{2 / 2 0 0 9}$ & $\mathbf{2 / 2 0 1 0}$ & $\mathbf{2 / 2 0 1 1}$ & $\mathbf{2 / 2 0 1 2}$ \\
\hline \multirow{4}{*}{ Humanidades } & Alto Prestígio & 9 & 11 & 13 & 12 & 16 & 12 \\
\cline { 2 - 8 } & Médio Prestígio & 9 & 11 & 13 & 15 & 15 & 12 \\
\cline { 2 - 8 } & Baixo Prestígio & 9 & 16 & 18 & 18 & 22 & 18 \\
\hline \multirow{4}{*}{ Saûncias } & Alto Prestígio & 6 & 10 & 10 & 17 & 14 & 10 \\
\cline { 2 - 8 } & Médio Prestígio & 9 & 11 & 14 & 11 & 14 & 13 \\
\cline { 2 - 8 } & Baixo Prestígio & 9 & 14 & 16 & 14 & 15 & 13 \\
\hline & Alto Prestígio & 5 & 7 & 11 & 11 & 12 & 12 \\
\cline { 2 - 8 } & Médio Prestígio & 7 & 12 & 15 & 16 & 15 & 14 \\
\cline { 2 - 8 } & Baixo Prestígio & 7 & 15 & 20 & 19 & 19 & 18 \\
\hline
\end{tabular}

Fonte: Tabela elaborada pelas autoras com base nos dados de UnB, 2013.

Na tabela em questão, observa-se que, para os cursos de alto prestígio na área de humanidades, o percentual de cotistas se mantém um pouco instável até 2010, aumentando em 2011 e voltando a cair. Acredita-se que esse pico alcançado em 2011, se deu devido a um maior número de inscrições homologadas pelo sistema.

Observa-se um comportamento diferente para os cursos de alto prestígio na área de ciências, no qual o pico dessa área ocorre em 2010 e depois volta cair, apesar dessa queda se manter constante se compara aos anos anteriores a 2010. Na área de saúde, mesmo com o aumento de homologações em 2011, a demanda dos alunos cotistas se mantém estável para essa área.

Nos cursos de médio prestígio, na área de humanidades, observa-se que a demanda se manteve crescente até o ano de 2011, caindo em 2012 quanto o número de candidatos homologados volta cair, entretanto, para área de ciências e de saúde, o fenômeno ocorre de maneira diferente, apesar da queda de candidatos homologados e 2012 a demanda se mantém estável em ambas as áreas, possuindo uma ligeira queda, mas nada que fuja do padrão doa nos anteriores. 
Nos cursos de baixo prestigio em todas as áreas, observa-se que ocorre um grau menor de oscilações. Cardoso (2008), conclui em sua pesquisa que os candidatos ao sistema de cotas tendem a buscar cursos de baixo prestígio, o que pode ser explicada por condições socioeconômicas. Esse padrão apresentado mostra-se contínuo nos anos seguintes das cotas, no qual a demanda de candidatos aos cursos de baixo prestígio se mostra maior do que a demanda das demais áreas.

\section{c) COTAS NOS CURSOS DE ALTO PRESTÍGIO}

A tabela 10mostra a evolução do percentual da demanda de candidatos cotistas e não cotistas aos cursos de maior prestígio.

Tabela 10 - Demanda de cotistas e não cotistas nos cursos de alto prestígio no período de 2/2007 a $2 / 20012$

\begin{tabular}{|c|c|c|c|c|c|c|c|c|c|c|c|c|}
\hline \multirow{2}{*}{ Área } & \multicolumn{2}{|c|}{$2 / 2007$} & \multicolumn{2}{|c|}{$2 / 2008$} & \multicolumn{2}{|c|}{$2 / 2009$} & \multicolumn{2}{|c|}{$2 / 2010$} & \multicolumn{2}{|c|}{$2 / 2011$} & \multicolumn{2}{|c|}{$2 / 2012$} \\
\hline & NC & C & $\mathrm{NC}$ & $\mathrm{C}$ & $\mathrm{NC}$ & $\mathbf{C}$ & NC & $\mathbf{C}$ & $\mathrm{NC}$ & $\mathrm{C}$ & $\mathrm{NC}$ & C \\
\hline Hum & 91 & - & 89 & 11 & 87 & 13 & 8 & 12 & 86 & 14 & 88 & 12 \\
\hline Ciê & 94 & 6 & 90 & 10 & 90 & 10 & 83 & 17 & 86 & 14 & 90 & 10 \\
\hline Saúde & 95 & 5 & 93 & 7 & 89 & 11 & 89 & 11 & 88 & 12 & 88 & 12 \\
\hline
\end{tabular}

Fonte: Tabela elaborada pelas autoras com base nos dados de UnB, 2013.

Observa-se que, após 2007 (implementação do ReUni), a demanda de alunos cotistas aos cursos de alto prestígio aumentou, se mantendo constante com o decorrer dos anos para a área de saúde. $\mathrm{Na}$ área de humanidades, a demanda dos alunos mostrou-se instável no decorrer dos anos. E na área de Ciências a demanda se mostra mais constante que nas demais áreas, tendo seu pico em 2010 e logo após retomando a sua estabilidade.

É importante ressaltar que a demanda de alunos negros na área de saúde é crescente e constante durando o período analisado, mostrando que as cotas possuíram um papel importante, acrescentando mais alunos negros a cursos cuja a demanda anteriormente era pequena e se mostrando também mais eficiente que nos cursos de baixo prestigio. Isso ocorre devido aos cursos de baixo prestigio já possuírem uma demanda de alunos negros a universidade e com as cotas essas demandas aumentaram em uma pequena quantidade, enquanto nos cursos de saúde a demanda vem se mostrando crescente.

\section{APONTAMENTOS SOBRE A POLÍTICA DE COTAS RACIAIS NA UNIVERSIDADE DE BRASÍLIA}

O presente trabalho dividiu o período de vigência das cotas raciais em 2 momentos: antes e depois da implementação do ReUni, analisando a porcentagem de alunos cotistas e não cotistas que ingressaram na universidade durante os 9 dos 10 anos em que a política 
vigorou. Não foram analisados os 10 anos da política, uma vez que em 2013 o foco da universidade passou a ser as cotas sociais, que apesar de possuírem um recorte PPI (preto, pardo e indígena), esse sistema possui outras características que alteraram o foco da pesquisa da universidade.

Foi possível observar que antes da implementação do programa ReUni, a procura pela universidade vinha caindo e após a implementação do programa a busca pela universidade aumentou novamente, entretanto, com o passar dos anos a procura vem caindo novamente, o que pode ser atribuído ao redirecionamento de estudantes para rede de ensino privado, através de programas incentivados pelo governo, como Fies e ProUni, fato este que justificaria as oscilações na demanda da universidade e pôr fim a queda na procura.

Levou-se em consideração para essa conclusão as mudanças no reconhecimento de candidatos da universidade, que buscavam caracterizar candidatos que realmente fossem aptos a participar do sistema e minimizar possíveis fraudes.

Em seu trabalho, Cardoso (2008) mostra que existiam cursos em que nenhum aluno negro ingressava, tais como relações internacionais, arquitetura, desenho industrial, história, engenharia mecatrônica, física. Com a implementação das cotas raciais, cursos que possuíam essa defasagem de alunos negros passaram a receber alunos negros a cada semestre, construindo um espaço mais igualitário na universidade.

Portanto, a política racial da universidade cumpriu com seu dever, e conforme observado, a política foi altamente monitorada e sofreu alterações sempre que necessário para que essa alcançasse seus objetivos. A política racial avançou no sentido de garantir a igualdade de acesso à universidade, mais também buscou equilibrar o percentual de alunos negro e não negro dentro da universidade, alcançando seu objetivo com as cotas que apesar de ter sido uma política temporária, esta causou grande impacto na universidade.

Conclui-se que com o decorrer dos anos em que o sistema de cotas vigorou, estas agruparam mais alunos negros nos cursos de baixo prestígio e sua procura foi mais elevada nas áreas de humanidades e de saúde. Na área de saúde, notou-se uma demanda mais consistente para todas as áreas de prestígio, ao contrário do que ocorreu na área de ciências, onde a demanda dos cotistas é menor e sofre com mais inconstâncias.

Portanto, a política racial da universidade cumpriu com seu objetivo e, conforme observado, a política foi monitorada e sofreu alterações sempre que necessário para que essa alcançasse seus objetivos. A política racial avançou no sentido de garantir a igualdade de acesso à universidade, mas também buscou equilibrar o percentual de alunos negro e não negro dentro da universidade, alcançando seu objetivo com as cotas que apesar de ter sido uma política temporária, esta causou grande impacto na universidade.

\section{CONSIDERAÇÕES FINAIS}


Esse trabalho buscou analisar a política de cotas raciais implementada na Universidade de Brasília, como ela impactou o acesso de alunos negros ao sistema, e observar se a política cumpriu seu papel de redistribuição de alunos negros na universidade. Analisou-se o número de ingressos pelo sistema ao longo dos anos de vigência da política, a quantidade de alunos com inscrições homologadas pelo sistema e o comportamento dos alunos nos cursos.

Como uma política compensatória, o sistema de cotas raciais busca a equiparação de direitos entre negros e brancos. Desta forma, a política de cotas raciais visa reparar danos de geração passadas, focalizando-se no grupo de negros do país, além de possuir sua justificativa em uma noção de direitos sociais, a fim de diminuir os impactos causados pela criação de uma cultura injusta, como se observa no caso racial.

Atualmente, o programa de cotas raciais encontra-se praticamente extinto na universidade, dando oportunidade para um novo programa de cotas sociais, no qual ocorre a reserva de vagas para estudantes que concluíram o ensino médio em instituições de ensino público.

Os dados revelaram que o programa de cotas raciais na universidade contribuiu para aumentar o acesso de alunos negros à universidade e redistribuí-los entre os cursos, além de mostrar que os candidatos negros buscam cursos de menor prestígio social e, de forma crescente, cursos da área de saúde.

Portanto, concluiu-se que o programa de cotas raciais foi valido e cumpriu seu objetivo de redistribuição de alunos entre os cursos, além de aumentar o acesso de alunos negros à Universidade de Brasília, principalmente, nos cursos de saúde, uma das áreas com maior demanda de alunos cotistas.

\section{REFERÊNCIAS}

BARCO, S. Políticas focalizadas. In: OLIVEIRA, D. A.; DUARTE, A..; VIEIRA, L. F (Org.). Dicionário: trabalho, profissão e condição docente. Belo Horizonte: UFMG/Faculdade de Educação, 2010.

BARROS, L. III Conferência Mundial contra o racismo. Revista Estudos Feministas, Florianópolis, v. 10, n. 1, p. 169-170, 2002.

BOBBIO, N. A era dos direitos. Rio de Janeiro: Campus, 1992.

BRASIL. Lei $\mathrm{n}^{\circ} 10.558$, de 13 de novembro de 2002. Cria o Programa Diversidade na Universidade, e dá outras providências. Disponível em: <http://www.planalto.gov.br/ ccivil_03/leis/2002/L10558.htm>. Acesso em: 30 abr. 2016. 
Artigo

doi: $10.20396 /$ rho.v18i1.8645867

BRASIL. Lei n ${ }^{\circ} 12.711$, de 29 de agosto de 2012. Dispõe sobre o ingresso nas universidades federais e nas instituições federais de ensino técnico de nível médio e dá outras providências. Disponível em: <http://www.planalto.gov.br/ccivil_03/_ato20112014/2012/lei/112711.htm>. Acesso em: 30 abr. 2016.

CARDOSO, C. B. Efeitos da política de cotas na Universidade de Brasília: uma análise do rendimento e da evasão. 2008. 134 f. Dissertação (Mestrado em Educação) Faculdade de Educação, Universidade de Brasília, Brasília, 2008.

CARVALHO, J. J. de.; SEGATO, R. L. Plano de metas para a integração social, étnica e racial da Universidade de Brasília. 2002. Mimeo. 3 p.

CURY, C. R. J. A educação básica no Brasil. Educação e Sociedade. Campinas, n. 80, p. 169-201, set. 2002.

FELICIANO, T.; DAVID V. O. B. Política social compensatória ou emancipatória: A contribuição de programas sociais para a autonomia dos beneficiários. Nampula:

Universidade Pedagógica, 2014.

GARCIA, F. A. da. C. Uma análise quantitativa do sistema de cotas raciais na Universidade de Brasília. 2013. 85 f. Monografia (Pedagogia). Universidade de Brasília, Brasília, 2013.

GIL, A. C. Como elaborar projetos de pesquisa. São Paulo: Atlas, 2002.

INSTITUTO DE PESQUISA ECONÔMICA APLICADA. Secretaria de Políticas de Promoção da Igualdade Racial. IPEA. Situação social da população negra por estado. Brasília, 2014.

INSTITUTO NACIONAL DE ESTUDOS E PESQUISAS EDUCACIONAIS ANÍSIO TEIXEIRA. INEP. Censo da educação superior 2014. Brasília, 2014.

KERSTENETZKY, C. L. Políticas sociais: focalização ou universalização. Revista de Economia Política, v. 26, n. 4, p. 104, 2006.

MORAES, W. C. S. de. Ações afirmativas e o acesso de negros na educação superior: um estudo de caso do Instituto Luther King - ILK. 2009. 158 f. Dissertação (Mestrado em Educação) - Universidade Católica Dom Bosco, Campo Grande, 2009.

OLIVEIRA, R. O direito à educação. In: OLIVEIRA, R.; ADRIÃO, T. Gestão, financiamento e direito à Educação: análise da Constituição Federal e da LDB. 3. ed. São Paulo: Xamã, 2007.

PAIXÃO, M. (Org.). Relatório anual das desigualdades raciais no Brasil 2009-2010. Constituição cidadã, seguridade e seus efeitos sobre as assimetrias de cor ou raça. Rio de Janeiro: Garamond, 2010. 
UNIVERSIDADE DE BRASÍLIA. Agência UnB. Negro precisa ser brilhante para se destacar no meio acadêmico, diz defensor de cotas raciais. 2009. Disponível em: <http://unb.br/noticias/unbagencia/cpmod.php?id=38385>. Acesso em: 30 abr. 2016.

UNIVERSIDADE DE BRASÍLIA. UnB. Análise do sistema de cotas para negros na Universidade de Brasília: Período $2^{\circ}$ semestre de 2004 ao $1^{\circ}$ semestre de 2013. 2013. Disponível em: < http://unb2.unb.br/administracao/decanatos/deg/downloads/index/ realtorio_sistema_cotas.pdf $>$. Acesso em: 07 mar. 2017.

VELLOSO, J. Rendimento no curso e no concurso: cotistas e não-cotistas de dois vestibulares na UnB. Brasília: NESUB; Ed. da UnB, 2009. mimeo. 23p.

VELLOSO, J. Vestibular com cotas para negros na UnB: candidatos e aprovados nos exames. Brasília: NESUB; Ed. da UnB, 2005. mimeo. 35p.

\section{Notas}

\footnotetext{
${ }^{1}$ Bacharel em gestão de políticas públicas pela Universidade de Brasília (UnB). Desenvolve pesquisa sobre políticas de acesso para negros ao ensino superior.

${ }^{2}$ Catarina de Almeida Santos - Professora Adjunta da Universidade de Brasília, Doutora em Educação pela USP, membro do Comitê Editorial da Revista Retratos da Escola, Vice-coordenadora da pesquisa Institucionalização da EaD nas Universidades Federais no Centro-Oeste e coordenadora da mesma pesquisa na Universidade de Brasília. Desenvolve estudos e pesquisas nas áreas: políticas públicas e institucionalização da educação a distância; e, políticas públicas e avaliação da educação básica.

3 Doutora em Educação pela Universidade de Brasília. É professora do Departamento de Planejamento e Administração da Universidade de Brasília - UnB. Desenvolve estudos e pesquisas nas áreas: acesso e permanência na educação superior (Rede Universitas/BR); políticas públicas e institucionalização da educação a distância; e, políticas públicas e avaliação da educação básica

${ }^{4} \mathrm{Na}$ tabela estão descritos a quantidade total de inscritos, levando em consideração o quantitativo de candidatos inscritos e que se encontraram ausentes durante a realização da entrevista.

5 Cardoso (2008) observou que o número de candidatos inscritos no vestibular é proporcional para ambos os sexos, não havendo nenhum tipo de sobreposição nesse quesito.
}

Submetido em: 30/04/2016

Aprovado em: 20/11/2017

Publicado em: 26/03/2018 